\title{
Secondary identifier for positive identification in DVI
}

\author{
Lay See Khoo ${ }^{1,2 *}$, Poh Soon Lai ${ }^{2}$, Ahmad Hafizam Hasmi ${ }^{2}$ and Mohd Shah Mahmood ${ }^{2}$ \\ ${ }^{1}$ Centre for Southeast Asia Disaster Prevention Research Initiative (SEADPRI), Institute for Environment and Development (LESTARI), Universiti Kebangsaan \\ Malaysia (UKM), Malaysia \\ ${ }^{2}$ National Institute of Forensic Medicine (NIFM), Hospital Kuala Lumpur, Malaysia
}

\begin{abstract}
In the context of mass fatality incident, it is of utmost importance to identify the victims rapidly and accurately, both for judicial reasons and to provide closure for family members. Disaster Victim Identification (DVI) work is an interdisciplinary manner, engaging the services of experts in various disciplines, comprising of pathologists, anthropologists, odontologists, radiologists, fingerprint and DNA experts to work collaboratively towards the identification of victims. The DVI process is conducted by adopting the fundamental principle where the highest possible quality standards should be applied and victims are to be treated with dignity and respect, in accordance to the internationally recognised INTERPOL DVI guide. The primary identifiers are the most reliable means of identification. They are fingerprint analysis, comparative dental analysis and DNA analysis. Secondary means of identification include personal description, medical findings and medical records as well as evidence and clothing found on the body. Most often than not, secondary identifiers are often used to complement the primary identifiers. However, there is always an exception. This paper highlights a case of the Dauphin helicopter crash in which identifications for all the victims were done using only secondary means of identification. Having said that, victims' bodies were released to family members without awaiting the DNA result. 24 hours later, the DNA analysis results were matched and confirmed the identity of the victims to be correct.
\end{abstract}

\section{Introduction}

Victims of a mass disaster are identified on the basis of an assessment of multiple factors. The degree to which bodies are damaged, the time bodies have been left exposed and the associated changes in the condition of bodies influence the nature and quality of post mortem data and the applicability of specific methods of identification [1]. Methods of identification used in cases of disasters must be scientifically sound, reliable, applicable under field conditions and capable of being implemented within a reasonable period of time. Thus the primary and most reliable means of identification are fingerprint analysis, comparative dental analysis and DNA analysis. Unique serial numbers from medical implants may also be reliable identifiers in the aspect of proving identity. Secondary means of identification include personal description, medical findings and medical records as well as evidence and clothing found on the body. These means of identification serve to support identification by other means and are normally not sufficient to be used as a sole means of identification and cannot be standalone to prove identity of disaster victims. Secondary identifiers are often used to complement the primary identifiers. To ensure that the victims are identified as quickly and as efficiently as possible, a multidisciplinary expert team comprising of the pathologists, odontologists, radiologists, fingerprint and DNA experts, are deployed to work as soon as practicable during a mass disaster incident. This paper highlights a case of the Dauphin helicopter crash in which identifications for all the victims were done using only secondary means of identification.

\section{Case study}

The Eurocopter AS365N2 Dauphin helicopter, carrying six people including the pilot, was en route from Kuantan to Subang, crashed in a rubber estate in Semenyih, Kajang around 1655 hours on $4^{\text {th }}$ April 2015. Semenyih is a small town located $37 \mathrm{~km}$ South from the Kuala Lumpur city centre. The private secretary at Prime Minister Office and the Member of Parliament were among those on board the aircraft. There was only one female passenger, a citizen of Kyrgyzstan with 5 males on board. A resident from nearby village witnessed that the helicopter exploded mid-air before crashing and exploded another time upon hitting the ground in the rubber estate. It was raining cats and dogs during the incident.

\section{Scene phase}

Efforts made to recover the victims' bodies from the crash site commenced immediately by the Fire and Rescue Department the same evening after explosion report received from the eyewitness. First responder team from the Fire and Rescue Department, Royal Malaysia Police (RMP) as well as from the Malaysia Civil Defence Department (JPAM) was mobilised to retrieve the victims. The helicopter was shattered into pieces and the rotor blades and tail were all over the crash site (Figure 1). The DVI process was activated and various experts were mobilised to the crash site to appreciate the position of the bodies with the injuries sustained. The victims' bodies were found scattered around in a small valley in the vicinity to the flight recorder or the Black Box (Figure 2). The search operation was conducted in a systematic way and the small valley was divided into four sectors, i.e. Sector A, B, C and D. Human remains found by the search team were tagged HR (Human Remains) followed by the running number. On the same

Correspondence to: Lay See Khoo, National Institute of Forensic Medicine, Hospital Kuala Lumpur, Jalan Pahang, 50586, Kuala Lumpur, Malaysia, E-mail: khoolaysee@yahoo.com

Key words: disaster victim identification, DVI, secondary identifier and disaster

Received: November 03, 2016; Accepted: November 28, 2016; Published: December 02, 2016 


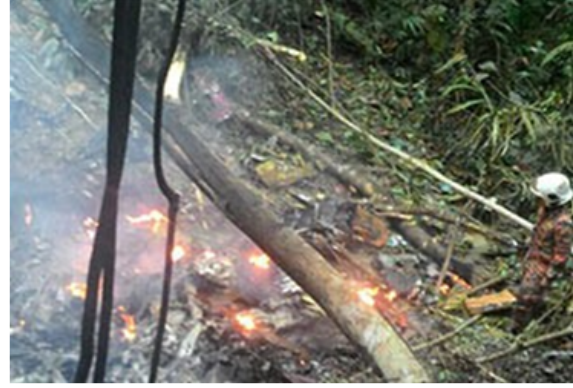

Figure 1. Crash site

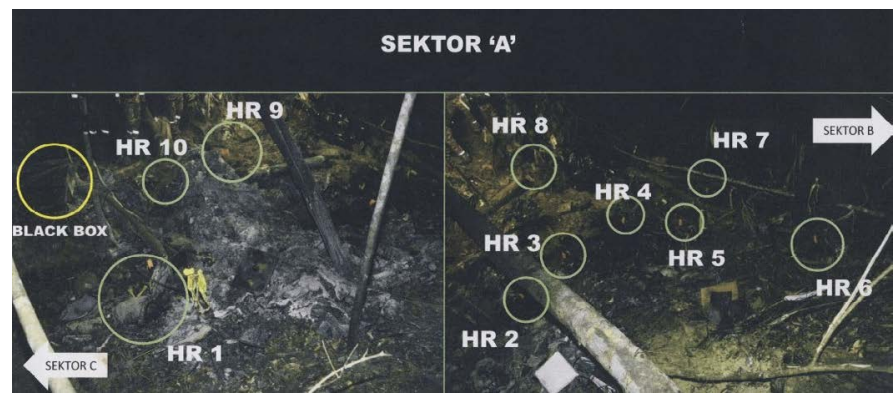

Figure 2. Location of the human remains and black box.

day at approximately 2130 hours, all the six bodies were successfully recovered.

\section{Postmortem phase}

All human remains recovered from the scene are to be examined in the Department of Forensic Medicine, Hospital Kuala Lumpur, which was identified as the Disaster Victim Identification (DVI) centre. At the same time, multidisciplinary expert team were mobilised to the DVI centre for the preparation of the recovered victims and subsequently to identify them. As soon as the arrival of the victims' bodies at the DVI centre, they were proceeded to the Postmortem Computed Tomography (PMCT) procedure before autopsy. The first body was examined at 2300 hours on $4^{\text {th }}$ April 2016 in the DVI centre. The examination processes and methods applied during this phase include photography, ridgeology (fingerprinting), radiology, odontology, DNA sampling and autopsy procedures. In addition to the examination of the human remains, property or personal belonging is to be meticulously examined, cleaned and stored. These property items may include jewellery, personal effects and clothing. All relevant PM information obtained during this phase is recorded on the pink INTERPOL DVI PM forms. Upon examination, the victims' bodies were charred and no fingerprints were able to be lifted. Femur bones were taken from all the victims for DNA analysis. PM examination for the last body was completed on the 0500 hours on $5^{\text {th }}$ April 2016. Below is the summary of the descriptions of human remains found on crash site (Table 1).

\section{Antemortem phase}

An antemortem (AM) team, mainly composed of investigators, needs to search for and to select the most relevant identification data. In this case, the accident was a closed disaster in which numbers of victims involved belonged to an identifiable group. There was a reference point with known passengers on board the helicopter. Next-of-kin or family members were available for interview. Detailed descriptions of the victims such as clothing, jewellery, tattoo, birthmarks and other abnormalities were obtained by the AM team. The last photograph
Table 1. Description of Human Remains found on site.

\begin{tabular}{|c|c|}
\hline Human Remains & Description \\
\hline HR1 & Victim 1 \\
\hline HR2 & Victim 2 \\
\hline HR3 & Victim 3 \\
\hline HR4 & Victim 4 \\
\hline HR5 & Victim 5 \\
\hline HR6 & Body part 1 \\
\hline HR7 & Body part 2 \\
\hline HR8 & Victim 6 \\
\hline HR9 & Body part 3 \\
\hline HR10 & Body part 4 \\
\hline
\end{tabular}

Table 2. Summary of the AM-PM matched secondary identifiers for all victims.

\begin{tabular}{|c|l|}
\hline Victim & AM-PM Matched Secondary identifiers \\
\hline 1 & The only female passenger \\
\hline 2 & Mercedes Benz car key with an unique screw attached \\
\hline 3 & Deformity on the left foot \\
\hline 4 & Bangle worn on left wrist \\
\hline 5 & Palm tree shape tattoo on chest \\
\hline 6 & $\begin{array}{l}\text { Traditional Malay costume worn in which it matched the last photograph } \\
\text { taken before boarding the aircraft }\end{array}$ \\
\hline
\end{tabular}

taken before the passengers went on board the aircraft was useful to be noted by the team. These information is recorded on the yellow INTERPOL DVI AM forms [2]. At the same time, blood samples were also taken from first degree relatives of the victims for DNA analysis except for the only female passenger from Kyrgyzstan.

\section{Reconciliation}

The identification of victims is realized by a process of comparison between AM data given by the families and PM data coming from the examination of the bodies during the PM phase. The function of the Reconciliation Centre is to match PM data with AM data with the view to identifying the deceased. In cases where there are reliable primary identifiers available, such as dental, ridgeology or DNA and those identifiers meet the requisite standards, these cases can be prepared for presentation to an identification board for confirmation. Nevertheless, in this case, the victims were matched using the strong secondary identifiers and presented to the identification board for endorsement. The bodies were then released to the next-of-kin on the same day without awaiting the DNA comparison results.

\section{Discussion}

Body parts found at the crash site were able to match to the respective victims during PM examination. The female victim was the first to be identified by exclusion criteria as she was the only female passenger on board. Identification based solely on photographs is notoriously unreliable and should be avoided at all costs. Visual identification by a witness may provide an indication of identity but is not sufficient for positive identification of victims of large-scale disaster, as the victims are often so traumatised that visual comparison is impossible and because relatives are frequently unable to cope with the psychological stress involved in confrontation with deceased victims [1]. As the female victim is a Kyrgyzstan national, there was some issues with the embassy and to obtain the first degree relatives blood. To overcome this issue, another option for AM DNA samples recommended by INTERPOL is the personal objects used by the deceased [3]. Profiles generated from personal objects can be directly compared to the DNAprofiles of victims. The female victim's DNA sample was later matched with the DNA profiles generated from her personal belongings in her 
rented apartment.

Country leaders and public figures were on board the Dauphin helicopter and thus the DVI team were strained to speed up the identification process. Most often than not, the victim identification is done based on the primary identifiers or on the combination of primary and secondary identifiers. However, in this particular case, with the strong secondary identifiers available both from the AM and PM data the DVI team experts were able to confidently confirm the identity of the victims without waiting for the DNA results. Having said that, there might be risk of mistakes using secondary identifiers leading to false exclusions or misidentifications. Caution needs to be exercised and various factors need to be weighed before coming to a conclusion.

\section{Conclusion}

Mass disasters with a large number of unknown victims are among the biggest challenges for the DVI team. The DVI process will be complicated if the incident is of media and national interest. The positive identification for the victims on board using secondary identifiers were indeed a bold and daring act. Nevertheless, the examination of the scene, photograph taken before boarding the aircraft, well collected AM data as well as other unique features obtained from the PM examination, the DVI experts were able to confirm the identity of the victims in less than 12 hours. Thus closures were given to the family members and public to mourn and grieve for the loss of the country leaders and public figures.

\section{Acknowledgement}

The National Institute of Forensic Medicine (NIFM) greatly acknowledges the tremendous support from the Director General of Health and the Director of the Hospital Kuala Lumpur particularly on the emergency disaster funding. NIFM also indebted to all forensic pathologist, odontologist, radiologist, DNA specialist and mortuary technicians for making this operation a success. NIFM would like to express gratitude towards the Royal Malaysia Police (RMP), Fire and Rescue Department, Malaysia Civil Defence Department and other first responders involved in the search and recovery operation as well as the transportation of human remains to the mortuary. Finally, the NIFM would like to advance appreciation to the work provided by all staff of Department of Forensic Medicine, Hospital Kuala Lumpur for their full support in the DVI operation.

\section{References}

1. INTERPOL, Disaster Victim Identification DVI Guide, The International Criminal Police Organization. (2014)

2. Schuliar Y, Knudsen PJT (2012) Role of Forensic Pathologists in Mass Disaster Forensic Sci Med Pathol 8: 164-173. [Crossref]

3. Montelius K, Lindblom B (2012) DNA Analysis in Disaster Victim Identification, Forensic Sci Med Pathol 8: 140-147. [Crossref]

Copyright: (C2016 Khoo LS. This is an open-access article distributed under the terms of the Creative Commons Attribution License, which permits unrestricted use, distribution, and reproduction in any medium, provided the original author and source are credited. 